\title{
Examining the level of women participation with and without higher education in form of humanitarian activities and charitable affairs
}

\author{
Masoumeh Cheraghi \\ MA, Department of Women Studies, Tehran Science and Research Branch, Islamic Azad \\ University, Tehran, IRAN \\ E-mail address: masoumeh_c@yahoo.com
}

Keywords: Participation, Social participation, Women, Special diseases, charitable affairs.

\begin{abstract}
The present article aims to examine the women's participation in charitable affairs of special diseases and to conduct a comparative comparison between women with higher education and women lacking such education. To this end, utilizing prominent sociological perspectives, first a coherent theoretical framework was provided and upon which research questions and hypotheses were proposed. Given the dependent variable of this research, a survey method was chosen for examining the women's participation in charitable affairs of special diseases and a comparative comparison between women with and without higher education. The research methodology in here is causative and a correlational investigation. Here, in this research the analysis unit is individual and the analysis level is a micro level. The independent variable in this research is education and the dependent variable is the social participation. The statistical population of this research included 750 women who were participating in special disease related charitable affairs. Quota sampling method and then simple random method were applied and as many as 254 people were selected. Tools for data collection were questionnaires. The findings obtained indicated the existence of a significant statistical relation between the independent variable of this research, i.e. education and dependent variable, i.e. social participation.
\end{abstract}

\section{INTRODUCTION}

One of the most important issues in each society is the political, economic, social and cultural growth and development which are on top of states' agenda due to credibility and significance they have. Hence, equipping thee society and people to attain such a situation is deemed an inevitable necessity. Also, from the view of social scientists, the development of each society involves a series of basics, standards and factors and in this respect, the active presence of people in different fields in the society and so-called their economic and social participation are considered to be very much critical and vital elements for the development of each society. In this regard, specifically the issue of social and cultural participation of women must be elaborated and investigated in detail so that basic grounds for the active participation of half of the society population are laid in different situations. In this article too, by utilizing credible scientific sources and methods and the views and theories by scholars at in detail so that basic grounds for the active participation of half of the society population are laid in different situations. In this article too, by utilizing credible scientific sources and methods and the views and theories by scholars in the area of women studies and social sciences, we choose to address the level of women participation with and without higher education in form of humanitarian activities and charitable affairs with emphasis placed on social diseases.

In each society, one of the main processes is the men's and women's level of participation in different affairs, because one of the factors that can play an effective role in the process of development and growth of a country is the public participation. As a main part of the community body, women encumber the social and familial responsibility and could take part in different scenes in line with men. Since women constitute half of the population in the society, half of the responsibility for participation in different aspects of each society is vested upon the women which necessitates the fact that they have an active and effective presence in their own society while playing familial roles like caring for husbands and child rearing as well as housekeeping. 
Consequently, through this we can argue that they can have a considerable role in political, social, cultural and economic development of the society. Volunteer presence and more participation in form of NGOs and attraction of peoples' attention and calling on them to take part is a more evolved and organized form compared to volunteer communities. In accordance with the activities which NGOs have created in different fields, one can assume to be effective the role these organizations create in the Iranian society. Currently, one of the policies and strategies of the health system is to support the participation of the women's NGOs in the area of expansion of women policies and improvement of the environment. Also, of other major policies in this connection is enhancement of arrangements and services and raising of awareness for girls and women with regards to preventing special and prevalent diseases, diagnosing them early, improving the culture of nutrition, and smoking abuse in accordance with the vulnerability of their physiological conditions in different life stages.

As stated earlier, with the advancement of human societies formation of different organizations and humanitarian and charitable affairs were brought out of a traditional form into a modern form. In fact, humanitarian and charitable affairs by women have a long history where in this modern world these services and activities are being conducted in form of mainly NGOs. These organizations are mainly private and non-profit entities and are administered with the financial help of members and benevolent people. Here, in this research given the discussions mentioned earlier, based on views of scholars and experts efforts are made the level of women's' participation in organizations and charitable affairs in Tehran are investigated. All religions and social reformists have instructed man a lot about kindness and benevolence. No doubt, Iranians were the only people who were followers of kindness. The Iranian culture and literature is filled with kindness and affection and the Iranian mysticism is unparalleled in terms of kindness and charity.

The climax of philanthropy of the Iranians could be found in Sa'di poems who states *Human beings are members of a body/ who are of one essence in creation*. In the Iranian society, the major women's activities in charitable and humanitarian activities were in traditional forms and in community forms, whereas these activities are currently followed by the women Red Crescent and NGOs. Hence, these measures have not yet been widely embedded among the masses and have often remained at the favorites level. Thus, we have not seen widespread and public membership in none of the NGOs. In recent years, establishment of bureaus and entities related to women in state sectors have been among factors for creation of growth or enhancement of women NGOs. Different statistics, in regard to women activities and their participation in different levels have all indicated raised literacy and wrens of women. The research is significant and necessary because the women's activities and measures in humanitarian and charitable affairs needed some scientific and all out investigation and assessment so that grounds for the participation of half of the society population are provided for taking part in different scenes in the community. In this regard, Iranian women, in accordance with religious beliefs and attitudes, moral commitments and values and their own emotional an delicate morale could contribute quite significantly to humanitarian and charitable affairs. The major and fundamental goal of this research is the level of women participation with and without higher education in form of humanitarian activities and charitable affairs with emphasis being laid on humanitarian and charitable affairs. In accordance with various investigations conducted by the author, it seems that few academic research have been performed on the said topic in Iran and there is simply a limited number of researches about women's NGOs of which we refer in the following:

Access to sustainable development needs organized participation of people in the society, including women. To access such a goal (the highest rate of participation), reduction of limitations and increase of legal powers are necessary. In this regard, a developmental approach necessitates that legal information, organizational powers and civil claims of women increase with a balanced pace, more specifically the fact that in recent years number of working women in state organizations have seen a considerable growth and such a trend will clarify some developmental approach and their effective presence in the decision making by organizations more than ever before. If this participation in the organizational decision process is accompanied with their increased legal 
knowledge, they can provide measures for increasing their working balance and increasing efficacy and effectiveness in the organization due to the fact they better understand and perceive their own professional and organizational conditions. The objective of this paper is this hypothesis that there exists a significant relationship between the female employees' legal knowledge in Tehran and their level of participation. The methodology in the theoretical section is attribution and in the empirical section (field-based), some statistical technics in analytical-descriptive way have been used. Findings revealed that there was a significant relationship between the female employees' legal knowledge and their organizational participation (Rokn Aldin Eftekhari and Rajab Poor Sadeghi, 2009). In this paper, attempts are made the main idea by Imam Khomeini in connection with the necessity of promotion of social trust level and participation seeking is considered to be investigated as an approach in politics and in Iran. For him, when conscious participation increases and is accompanied with peoples' self-confidence, some equal and mutual rights and commitments will be established between people and state systems and power relations will turn from a unilateral and public form (higher to lower) to reciprocal cooperation between the society and political entities. Subsequent to this situation, citizens will be connected to each other in form of equal people. Imam Khomeini criticizes theories which consider the masses as strange and regard no room for entrusting works and affairs to popular associations and NGOs. Imam Khomeini did not simply refer to theorizing and as a political leader in affairs, has presented practical strategies and endeavors for their accomplishment. It is evident that outlining the lines of such a society along with the characteristics of participation seeking does not mean negation of political entity which is one of the important entities in each society for attaining some political goals. Rather attention is focused on the fact should political and social actions are directed at networks at higher rate wherein there is trust in one and others, the civil society will achieve perceived opportunities easier and the government will too fulfill its own government in creating the ground for the formation of this ambition (Husseini Beheshti \& Hadavi, 2008).

Results by Samadi Rad's study (2008) with the title of mechanism for the promotion of women participation in economic and political dimensions suggested that the effects of the variable of education on thee women's political participation cannot be always approved of due to the weak laws and defects existing. Theses drawbacks could be have a negative impact and reduce their participation wishes. Therefore, attempts for reforming laws governing women conditions in the society are the main prerequisites for their promotion of social participation. Kurdi's research findings (2007) with the subject of factors affecting the women's attitude to political participation in the province of Golestan (case study: city of Gonbad Kavous) indicated that most women under study had positive attitudes to the political participation. In this regard, the education level has a pivotal role and the place of residence, age and profession of mother and ethnicity come second. Trajectory analysis coefficients demonstrate that literacy affected with age and place of residence is the most appropriate explanation factor for the variable of women's political participation attitudes. Results by Vosooghi and Yousefi Aghabin (2005) titled women social participation of the village of Aghkand, city of Myane demonstrated that the average rural women social participation shows a low level in accordance with this research and only $4 \%$ off the respondents had higher social participation. The participation of this number has been mainly in form of religious traditional participation, participation ritual birth ceremony and health center being some sort of reactive participation. On the other hand, according to statistical analyses performed, the existence of relationship between the rural women special participation with variables of women's attitudes to themselves (internal factors), age, education (contextual factors) and the level of their access to urban centers and also mass media (structural factors) have been confirmed. Since the late 1950s, the concept of participation and participatory development was raised as a major concept in social development discussions. The failure of these programs in fulfilling their own objectives reinforced this perception that lack of popular participation in designing, implementing and assessing programs have brought about the ground for their failure.

In response to setbacks in development programs, the concept of participation was brought into attention seriously and the processes strengthening people's participation were raised as major areas. 
To complete the discussions of this part of the research, and as a support for the research survey parts, thee theory of exchange and the Morris Halboaks view were utilized. The exchange theory focuses at concepts of rewards and punishment. For them, what results in the emergence of a behavior and causes its sustainability is the reward resulting from doing it. The main assumption of this perspective is humans expose behaviors from themselves which involve rewarding results. In this view, participation as a behavior will once grow when humans as participators see some rewards for it. The most significant theory in this approach is that of Homenz. He raised several fundamental propositions for explaining the human conduct that could be applied for explaining participatory behavior. These propositions are:

Proposition of success: if an act is committed by an individual, he receives rewards and the likelihood of its repetition will increase. Based on this proposition, if participation is expressed as a behavior on the part of an individual and receives rewards, the likelihood the person tends to that participatory behavior will increase. Proposition of value: Whatever the results of an action are more valuable for an individual, it is more likely he will again commit that action. Regarding participation, should its results and accomplishments render more value for the person compared to non-participatory behaviors; the likelihood for doing it will rise. The value of an action results from benefits and in Homenz view relates to rewards and punishment, i.e. the more an action involves more rewards and the less it yields costs, its repetition will be more possible. From among Homenz's propositions, the said two propositions provide more tangible and concrete concepts for explaining participatory behaviors. Hence, according to this theoretical pattern, behavior or tendency to participation is a function of benefits and its related costs; should the individual expects more profits and less costs in participation, he will have more inclination to participation. Participation is a social phenomenon which involves political and social implications. Participation as a social phenomenon is getting engaged in social values of membership; when people live their lives in the bottom of their own society norms and values, they are in fact involved in social life. Meanwhile, people could accept life manners, behaviors and social beliefs and habits or take positions against them.

Socialization as a sociocultural phenomenon means transference of values and practice and thinking styles to children, young people and strangers who have not yet accepted membership in groups. Socialization trends are in fact an increase of peoples' participation in social life. Morris Halboaks considers determination of social class position within the social hierarchy to be highly dependent on participation or taking profit of higher social activities. Therefore, in each society, there is an assessment of cat a certain level the needs related to that blessing. For Halboaks, this ideal or the highest significance is nothing but a certain form of social life which is meantime the most fruitful perceived social life. For Halboaks, the behaviors of human groups and cases are affected and influenced by their needs for enjoying and taking benefit of higher social activities or participation in social life. He writes about laborer's behaviors: to the extent workers find some more ability and competence will spend their additional income buying non-familial costs which involve some broad social aspects instead of finding a better house or reforming the situation at home. For example, in the area of close contact with groups in alleys and in their floors. Shotze also speaks of concrete chance concept by Weber. For him, achieving a favorable standardized result is by means of using a standardized instruction of a concrete chance. This concrete chance is not controlled by people; thus people accept that a concrete chance adapts to a subjective chance. Shotze states whatever the concrete chances are greater for the effectiveness of an instruction, typical deviancies will less occur. An instruction and a behavioral pattern, to the extent it involves a concrete chance, i.e. the means it offers will be objectively and actuality followed by agents and when their level of chance decreases they will lose by the same extent some social action course (Alavi Tabar, 2000).

Research hypothesis

1. It looks there is a significant relationship between women participation charitable affairs (special disease) ad their education. 
- Research theoretical model:

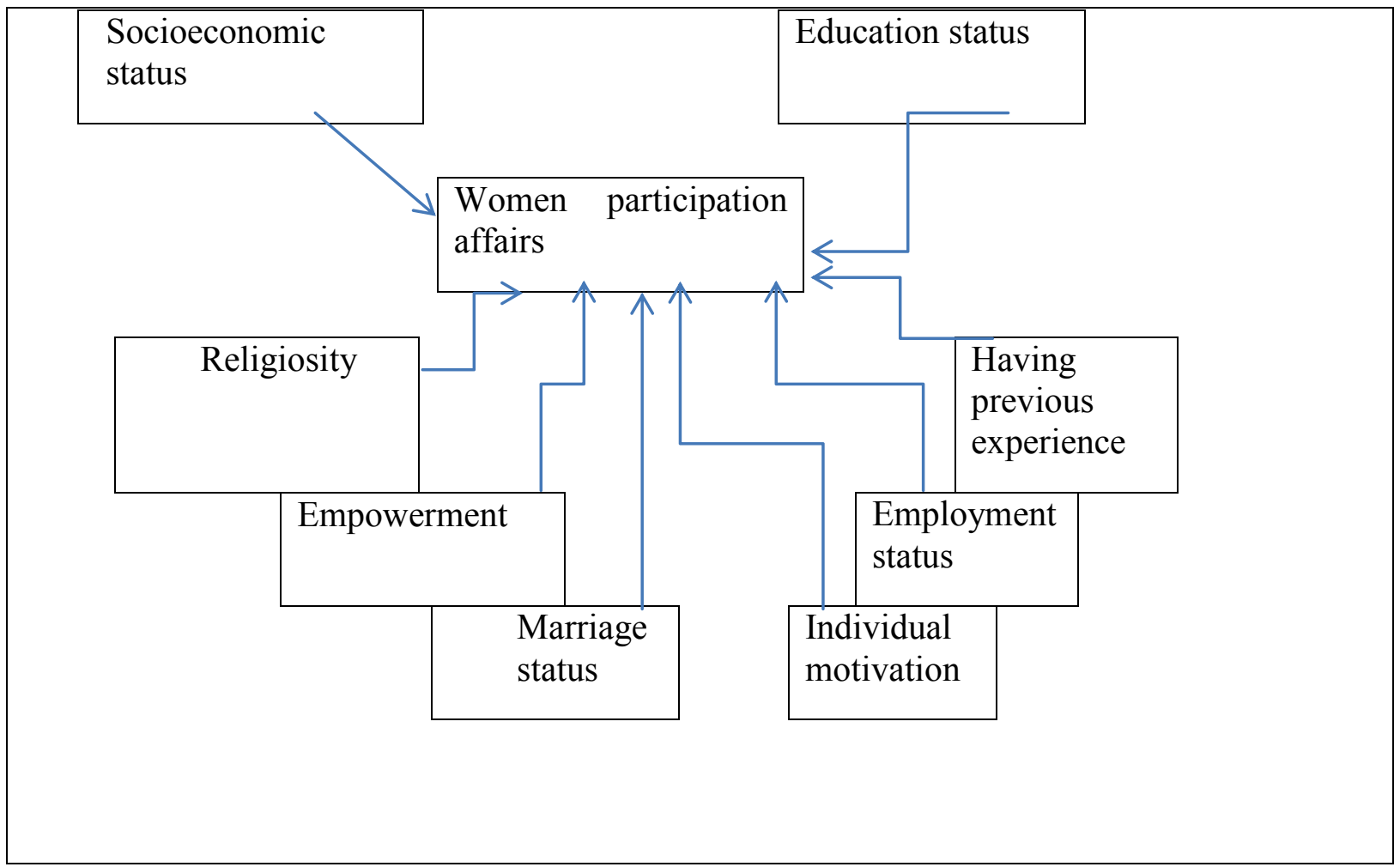

\section{METHODOLOGY}

In this research the methodology is causative and a correlational investigation. To collect data and information related to the research variables, questionnaires were used. Here, in this research the analysis unit is individual and the analysis level is a micro level. The independent variable in this research is education and the dependent variable is the social participation. The statistical population of this research included 750 women who were participating in special disease related charitable affairs (Mahak institution, hemophilia association and association of epilepsy and ...). Quota sampling method and then simple random method were applied and as many as 254 people were selected through the Cochran formula which constitutes the sample size. To determine validity level of the measuring tool, the formal (content) validity was applied. Here, in this method, counseling and interview with professors and scholars were also utilized. In this study, for determining the reliability and confidence and put it more exactly, the internal consistency of the items for measuring a combinational concept and variable, the Cronbach's alpha coefficient as applied which is $0 / 82$. Data were analyzed by descriptive statistics methods (average, standard deviation) and inferential statistics (Pearson).

\section{FINDINGS}

Given the fact our research object of study is examination of women participation in charitable works of special diseases and that we want to perform a comparative comparison between women with higher education, i.e. those who have degrees higher than diploma with women without higher education, i.e. those who have degrees lower than diploma. To this end, after the relevant tests which were seen above, the statistical test of comparison between the two groups was also carried out so to grasp the differences between the average of the two groups with and without higher education. 
Table 1. $T$ test for two independent groups for average differences

\begin{tabular}{|c|c|c|c|c|c|c|c|}
\hline & \multicolumn{2}{|c|}{$\begin{array}{l}\text { Test level for variances } \\
\text { equality }\end{array}$} & \multicolumn{5}{|c|}{$\mathrm{T}$ test for average equality } \\
\hline & $\mathrm{F}$ & \begin{tabular}{|l} 
Confidence \\
level
\end{tabular} & $\mathrm{t}$ & $\begin{array}{l}\text { Freedom } \\
\text { degree }\end{array}$ & $\begin{array}{l}\text { Confidence } \\
\text { level }\end{array}$ & $\begin{array}{l}\text { Average } \\
\text { differences }\end{array}$ & $\begin{array}{l}\text { Standard error of } \\
\text { differences }\end{array}$ \\
\hline 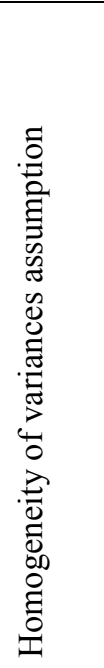 & $19 / 021$ & $0 / 000$ & $4 / 216$ & 252 & $0 / 000$ & $0 / 385$ & $0 / 09153$ \\
\hline 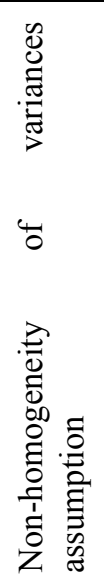 & & & $4 / 216$ & $244 / 17$ & $0 / 000$ & $0 / 385$ & $0 / 09153$ \\
\hline
\end{tabular}

Table (1) results indicate that the Leven's test is significance $(\mathrm{P}<0 / 000)$, thus the t value estimated is inappropriate with the combinational variance (assumption of variance equality). As seen, the $t$ estimated with the freedom degree of 252 and the error likelihood of $0 / 000$ equals $3 / 29$. Because the $t$ estimated $(4 / 216)$ in the table is greater than (3/29), thus the null hypothesis is not supported. We conclude that there is significant relationship in terms of women participation between the two groups with and without higher education and the average difference stands on one side of zero which means that in terms of the averse women's participation in charitable affairs between the two groups of women with and without higher education, i.e. people who have higher education have more participation in charitable affairs and are more present in the society.

\section{CONCLUSION}

In each society, one of the main processes is the men's and women's level of participation in different affairs, because one of the factors that can play an effective role in the process of development and growth of a country is the public participation. As a main part of the community body, women encumber the social and familial responsibility and could take part in different scenes in line with men. Since women constitute half of the population in the society, half of the responsibility for participation in different aspects of each society is vested upon the women who necessitate the fact that they have an active and effective presence in their own society while 
playing familial roles like caring for husbands and child rearing as well as housekeeping. Consequently, through this we can argue that they can have a considerable role in political, social, cultural and economic development of the society. In fact, the most vital element for the development of a society is the people of that society, i.e. men and women who must enjoy necessary and various skills. As Emil Durkheim states education is a process through which women learn styles to have some competencies and capacities in the society in the social, political and intellectual areas. The way participation is educated and necessary awareness for women is done by means of press, audio, visual media, NGOs, and numerous entities while being correspondent with conditions, talents and special motivations.

Women, currently can play an effective role in furthering development objectives a $\mathrm{d}$ sustainability and one can say that without women's participation, specifically the educated women in development and their active presence in all areas, it will be impossible to speak of fast advancement and progress in the society. Also, the level of women's activities in different affairs of the society depends on age and marriage and education level on the one hand and national facilities on the other hand. Volunteer presence and more participation in form of NGOs and attraction of peoples' attention and calling on them to take part is a more evolved and organized form compared to volunteer communities. In accordance with the activities which NGOs have created in different fields, one can assume to be effective the role these organizations create in the Iranian society. It appears to say that the output of the educated women is higher than that of the non-educated women. Along with cultural developments, transformations and variations in the area of economy and thee women's participation in generating income and increase of educational opportunities will result in a variety of groups and expansion of social ties and more women's group attachment as well as expansion of sources for women identification. Usually, people, specifically women have numerous social roles to ply which is a function of their membership in various groups and communities. Some roles involve more credibility and prestige for them. The dominant social identity is the one which defines more value and significance for the person. In recent decades, women having enjoyed academic education and their turning to economic activities, specifically in large cities have involved more values in the economy area and this has resulted in changing of marital and familial relations and promotion of social and economic situation of women. More, new identification has been set for women. The $t$ test of the two independent groups for the average differences indicated that there is a significant relationship between the two groups with and without higher education and the difference average stands on the side of zero where this demonstrates the average women's participation in charitable affairs is difference between the two groups of women wit $\mathrm{h}$ and without higher education and this participation among women with higher education is greater than women without higher education.

\section{Research recommendations}

Today, more girls and women enter schools. Despite all progress, years of negligence have resulted in higher rates of illiteracy among women, specifically rural women in developing countries. Unfortunately, social-cultural conditions in the society, particularly in low populated and underdeveloped areas have caused women not to see themselves as paralleled with men. In this regard, they have been faced with numerous difficulties and are considered to be highly vulnerable people due to exiting conditions. Applying women's abilities and talents with the intention of maximum utilization from the human work force in societies necessitates exact and scientific understanding of their activities. In developed countries with higher economic rates, women contribute significantly to a large production portion. Putting aside women does mean lac of using all production capabilities of the society which is made effective on the whole society. It is necessary that young, educated increase their own self-confidence and utilize more professional facilities. Meaningful participation of women in major decision making is not only useful for women; rather the society takes advance of it. Empowerment of women will raised the intellectual and cultural kevel of the society and women as raisers of the future generations, if become more able and competent $t$ the society will take profit from that. Countries will one become developed 
when they serve thinking and progress. The present article aims to examine the women's participation in charitable affairs of special diseases and to conduct a comparative comparison between women with higher education and women lacking such education. To this end, utilizing prominent sociological perspectives, first a coherent theoretical framework was provided and upon which research questions and hypotheses were proposed. Given the dependent variable of this research, a survey method was chosen for examining the women's participation in charitable affairs of special diseases and a comparative comparison between women with and without higher education.

\section{Research limitations}

1. One of the major limitations of this research is a lack of Persian sources which resulted in the researcher to spend hours searching for electronic sources

2. That which appeared to be a problem in the executive section was the completion of questionnaires among the benevolent people. Inclusion into this statistical population and drawing the attention of people was difficult and they responded to the questionnaires a long period of time after investigation

3. Conservative inclination of some of the people about variables of income and the like was also problematic

4. Establishing communications with some of the respondent was tricky.

\section{References}

[1] Alavi Tabar, A. (2000). Participation in administae4ration of urban affairs. Tehran: National Municipalities Organization.

[2] Rokn Aldin Eftekhari, A. R., Rajab Poor Sadeghi, A. (2008). Role of legal knowledge of employed women in the process of participation. Women research, 6(1): 55-74.

[3] Husseini Beheshti, S. A., \& Hadavi, H. (2008). Role of confidence building in increasing public participation from the view of Imam Khomeni. Quarterly of social sciences, 29:113-132.

[4] Kurdi, H. (2007). Factors affecting the women's approach towards political participation in the province of Golestan (Case study: City of Gonbad Kavous). Quarterly of Iranian social studies, 1(2): 111-123.

[5] Samadi Rad, A. (2008). Mechanisms for promotion of women's participations in political and economic dimensions. Journal of social welfare, 5(21): 99-122

[6] Vosooghi, M., \& Yousefi Aghabin, A. (2005). Sociological researches in the area of women social participation in the Aghkand village of the city of Myane. Humanities journal, 12(3): 123-139. 